Conclusion: Gout patients with/without two years adherence of urate-lowering agents does not have an impact on ESRD and all-cause mortality.

References: Nil

Disclosure of Interests: : None declared

DOI: 10.1136/annrheumdis-2020-eular.4008

\section{THU0425 ULTRASOUND DETECTED URATE CRYSTALS DEPOSITIONS ARE ASSOCIATED WITH ELEVATED CALPROTECTIN AND CRP INDICATING SUBCLINICAL INFLAMMATION; BASELINE RESULTS FROM THE NOR-GOUT STUDY}

H. B. Hammer ${ }^{1}$, G. Jensen ${ }^{2}$, L. Karoliussen ${ }^{1}$, L. Terslev ${ }^{3}$, E. A. Haavardsholm ${ }^{1}$, T. K. Kvien ${ }^{1}$, T. Uhlig'. ${ }^{1}$ Diakonhjemmet Hospital, Dept. of Rheumatology, Oslo, Norway; ${ }^{2}$ Diakonhjemmet Hospital, Oslo, Norway; ${ }^{3}$ Centre for Rheumatology and Spinal Diseases, Rigshospitalet, University Hospital at Glostrup,

Copenhagen, Denmark

Background: Ultrasound detects depositions of monosodium urate (MSU) crystals in gout patients. The OMERACT ultrasound group has developed definitions for elementary lesions in gout including the double contour (DC) sign (depositions of crystals on the surface of cartilage) and tophus (larger hypoechoic aggregation of crystals, usually well delineated). Calprotectin is a major granulocyte protein found to be sensitive to reflect the level of inflammation in several immunological diseases. There may be an association between low grade inflammation and co-morbidity (including cardio-vascular pathology) in gout patients.

Objectives: To explore whether the extent of depositions (e.g. DC and tophi) was associated with inflammation in gout patients.

Methods: The baseline data from NOR-GOUT, a prospective observational study of patients with crystal-proven gout with increased serum urate levels $(>360$ $\mu \mathrm{mol} / \mathrm{L})$, were presently used. All patients had an extensive ultrasound examination(GE E9 machine, grey scale $15 \mathrm{MHz}$ ) to assess MSU depositions (DC and tophi) with bilateral assessment of radiocarpal joint, MCP 2, insertion of triceps and quadriceps, proximal and distal patellar and the Achilles tendon, cartilage of distal femur (maximal flexed knee), the talar cartilage of tibiotalar joint and MTP 1 joint. The degree of elementary lesions was semi-quantitatively scored 0-3 ( $0=$ none, $1=$ possible, $2=$ certain, $3=$ major deposits). Total sum scores of DC and tophi were calculated and the associations with calprotectin (plasma assessed by ELISA (Calpro), normal levels $<910 \mu \mathrm{g} / \mathrm{L}$ ) as well as C-reactive protein (CRP, assessed as a routine at our laboratory, normal levels $<4 \mathrm{mg} / \mathrm{L}$ ) were explored. Correlations were performed by use of Spearman and differences between groups were investigated by Mann-Whitney tests.

Results: A total of 111 patients who had calprotectin assessed were included in the study (92\% men, mean (SD) age 54.5 (14.5) years, disease duration 7.1 (6.6) years) when initiating MSU lowering treatment. The mean (SD) sum sore DC and tophi was 9.1 (7.8), calprotectin 780 (500) $\mu \mathrm{g} / \mathrm{L}$, CRP 7 (15) mg/L, serum urate (SUA) 505 (87) $\mu \mathrm{mol} / \mathrm{L}$, creatinine 96 (18) $\mu \mathrm{mol} / \mathrm{l}$ and eGFR 79 (20) $\mathrm{ml} / \mathrm{min} / 1.73 \mathrm{~m}^{2}$. Table 1 shows significant correlations between sum sore DC/tophi and calprotectin, CRP, SUA, creatinine and eGFR. Increased calprotectin levels $(\geq 910 \mu \mathrm{g} / \mathrm{L})$ were found in $28 \%$ and increased CRP ( $\geq 4 \mathrm{mg} / \mathrm{L})$ in $39 \%$. Patients with increased vs normal levels of calprotectin had significantly higher levels of DC/tophi depositions (mean (SD) 13.0 (10.4) vs 7.4 (5.8), $\mathrm{p}=0.01$ ), and similar was found for CRP (11.4 (9.5) vs 7.6 (6.2), $\mathrm{p}=0.033$ ) (illustrated in table 2).

Conclusion: In gout patients, higher load of MSU depositions was associated with increased inflammatory markers. This indicates that the amount of depositions is associated with higher inflammatory activity, which could have systemic implications.

\begin{tabular}{lccccc}
\hline & Sum score DC and tophi & Calprotectin & CRP & SUA & Creatinine \\
\hline Calprotectin & $0.31^{*}$ & & & & \\
CRP & $0.29^{*}$ & $0.65^{\star *}$ & & & \\
SUA & $0.31^{\star *}$ & $0.22^{*}$ & 0.19 & & \\
Creatinine & $0.34^{\star *}$ & $0.25^{*}$ & 0.15 & $0.36^{* *}$ & \\
eGFR & $-0.38^{\star *}$ & $-0.27^{*}$ & $-0.21^{*}$ & -0.18 & $-0.86^{\star *}$ \\
& & & & &
\end{tabular}

${ }^{*} p \leq 0.05,{ }^{* *} p \leq 0.001$

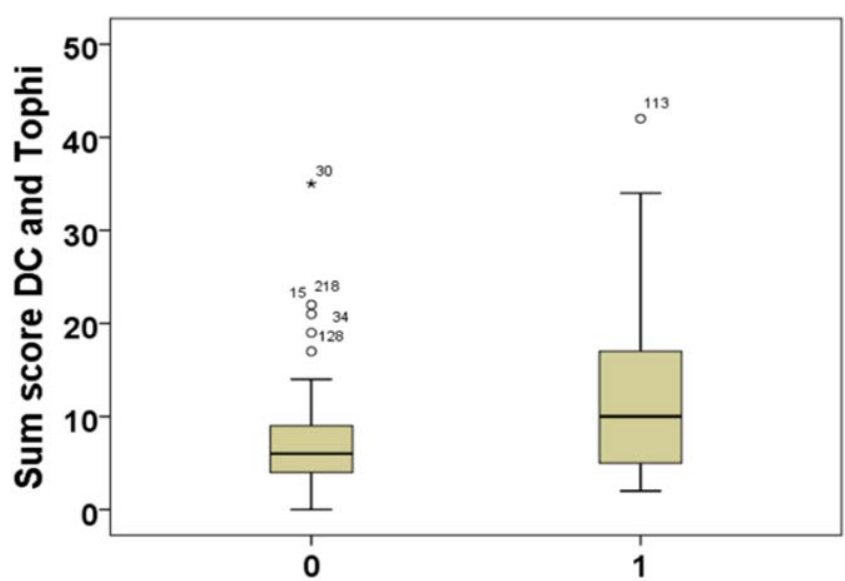

Calprotectin; $0=$ Normal, $1=$ Increased

Disclosure of Interests: : Hilde Berner Hammer Consultant of: Has received fees as consultant from Roche, AbbVie and Novartis., Speakers bureau: Has received fees for speaking from AbbVie, BMS, Pfizer, UCB, Roche, MSD and Novartis, Gro Jensen: None declared, Lars Karoliussen: None declared, Lene Terslev Speakers bureau: LT declares speakers fees from Roche, MSD, BMS, Pfizer, AbbVie, Novartis, and Janssen., Espen Andre Haavardsholm Grant/ research support from: Research funding from Pfizer, UCB, Roche, MSD and AbbVie, Consultant of: Pfizer, Speakers bureau: Pfizer, UCB, Roche, and AbbVie,, Tore K. Kvien Grant/research support from: Received grants from Abbvie, Hospira/Pfizer, MSD and Roche (not relevant for this abstract)., Consultant of: Have received personal fees from Abbvie, Biogen, BMS, Celltrion, Eli Lily, Hospira/Pfizer, MSD, Novartis, Orion Pharma, Roche, Sandoz, UCB, Sanofi and Mylan (not relevant for this abstract)., Paid instructor for: Have received personal fees from Abbvie, Biogen, BMS, Celltrion, Eli Lily, Hospira/Pfizer, MSD, Novartis Orion Pharma, Roche, Sandoz, UCB, Sanofi and Mylan (not relevant for this abstract)., Speakers bureau: Have received personal fees from Abbvie, Biogen, BMS, Celltrion, Eli Lily, Hospira/Pfizer, MSD, Novartis, Orion Pharma, Roche, Sandoz, UCB, Sanofi and Mylan (not relevant for this abstract)., Till Uhlig Consultant of: Lilly, Pfizer, Speakers bureau: Grünenthal, Novartis

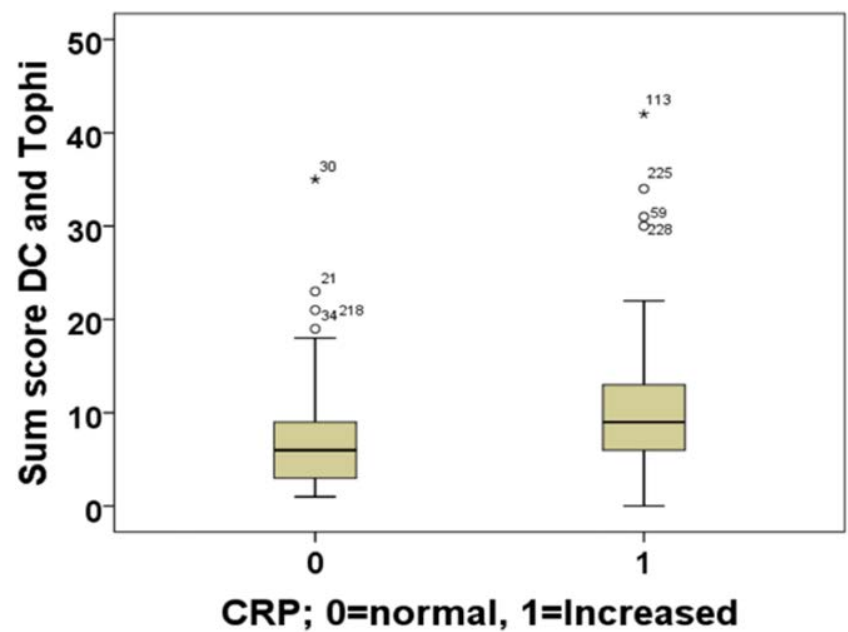

DOI: 10.1136/annrheumdis-2020-eular.2365

\section{THU0426 CLINICAL CHARACTERISTIC OF INFECTIOUS ULCERATION OVER TOPH}

Z. Huang ${ }^{1,2}$, T. LI ${ }^{3}$, X. Liu ${ }^{3} .{ }^{1}$ Guangdong Second Provincial General Hospital, Guangzhou, China; ${ }^{2}$ Brigham and Women's Hospital, Harvard Medical School, Boston, United States of America; ${ }^{3}$ Guangdong Second Provincial General Hospital, Guangzhou, China

Background: Infection in ulceration over tophi is the leading cause of sepsis in patients with gout, which is the main indication for surgery. Additionally, 
patients with infection will significantly prolonged wound closure time compared with those without infection. Investigation of infection in ulceration over tophi will improve our understanding of this critical issue.

Objectives: To describe the microbiological profile in ulceration over tophi, antibiotic susceptibility patterns of causative agents, and to study the prediction of infection in ulceration over tophi among patients with gout.

Methods: Patients with ulceration over tophi were prospectively enrolled. The clinical characteristics were recorded and microbiological specimens were taken on admission. Specimens were cultured for aerobic and anaerobic bacteria, and antibiotic susceptibility testing was performed for the culture isolates. Patients were divided into 2 groups according to having infectious ulceration or not and the potential risk factors for infectious ulceration over tophi were examined using univariate and multivariate logistic regression analyses.

Results: A total of 82 patients were included for analysis. 46 pathogens were isolated from 39 (47.6\%) patients, among which the top 3 were Staphylococcus aureus (43.5\%), Pseudomonas aeruginosa (17.4\%) and Enterococcus faecalis $(13.0 \%)$. Overall, the Gram-positive bacilli were more sensitive to gentamicin $(81.5 \%)$, amikacin $(88.9 \%)$, trimethoprim/sulfamethoxazole $(92.6 \%)$, nitrofurantoin $(96.3 \%)$, linezolid (100.0\%), teicoplanin (100.0\%) and vancomycin (100.0\%) whereas penicillin, oxacillin and ampicillin were $66.7 \%$ to $77.8 \%$ resistant. The Gram-negative bacilli were more sensitive to amikacin (84.2\%), cefoperazone/ sulbactam (84.2\%) and meropenem (89.5\%) whereas ampicillin, amoxicillin/ clavulanate, cefotaxime, cefazolin, piperacillin, trimethoprim/sulfamethoxazole and tetracycline were $68.4 \%$ to $100 \%$ resistant. Patients with infection had a higher rate of smoking history and type 2 diabetes, with higher levels of erythrocyte sedimentation rate, C-reactive protein and leucocyte, and lower level of albumin. In stepwise logistic regression analysis, type 2 diabetes (adjusted OR $5.064 ; 95 \% \mathrm{Cl}=1.430$ to 17.928 ) and albumin level (adjusted OR $0.855 ; 95 \%$ $\mathrm{Cl}=0.782$ to 0.935 ) were independent predictors of infection in ulceration over tophi.

Conclusion: Infection is common in ulceration over tophi. Different antibiotic susceptibility patterns were observed in Gram-positive bacilli and Gram-negative bacilli. Type 2 diabetes and low albumin level were associated with an increased risk of infection in ulceration over tophi. The data in this study will be beneficial for tailoring infection control measures in a way that improves outcomes of ulceration over tophi.

References:

[1] Huang Z, Liu X, Liu Y, et al. Clinical characteristics and risk factors of ulceration over tophi in patients with gout. International journal of rheumatic diseases 2019;22:1052-7.

[2] Xu J, Zhu Z, Zhang W. Clinical characteristics of infectious ulceration over tophi in patients with gout. The Journal of international medical research 2018;46:2258-64.

Table 1. Bacteria isolated from initial ulceration specimens taken on the first admission.

\begin{tabular}{lcc}
\hline Bacteria & Number $^{\star}(\mathrm{n}=46)$ & Proportion (\%) \\
\hline Gram-positive bacilli & 27 & $\mathbf{5 8 . 7}$ \\
Staphylococcus aureus & 20 & $\mathbf{4 3 . 5}$ \\
Enterococcus faecalis & 6 & 13.0 \\
Streptococcus mutans & 1 & 2.2 \\
Gram-negative bacilli & 19 & 41.3 \\
Pseudomonas aeruginosa & 8 & 17.4 \\
Klebsiella pneumonia & 4 & 8.7 \\
Enterobacter cloacae & 3 & 6.5 \\
Escherichia coli & 2 & 4.3 \\
Acinetobacter baumannii & 2 & 4.3 \\
\hline
\end{tabular}

* Number of ulceration

Disclosure of Interests: : None declared

DOI: 10.1136/annrheumdis-2020-eular.968

\section{THU0427 SHOULD FEBUXOSTAT-RESISTANCE BE ADDED TO CRITERIA FOR REFRACTORY GOUT? A PRELIMINARY STUDY}

Z. Huang ${ }^{1}$, W. Zhao ${ }^{1}$, D. Deng ${ }^{1}$, Y. Liu', S. Chen ${ }^{1}$, J. Chen ${ }^{1}$, T. LI ${ }^{1} .{ }^{1}$ Guangdong Second Provincial General Hospital, Guangzhou, China

Background: Refractory gout manifests as recurrent flares, chronic arthritis and progressive tophaceous deposits. Febuxostat is a widely-used potent serum urate-lowering reagent, but some gout patients cannot achieve target serum uric acid (sUA) after they used this reagent.

Objectives: To determine whether febuxostat-resistance should be a criterion for refractory gout, characteristics of gout patients who were resistance to febuxostat or allopurinol were compared.
Methods: This study was performed from December 2015 to December 2019. Medical records of gout patients who met the 2015 gout classification criteria [1] and undertook febuxostat (febuxostat group) or allopurinol (allopurinol group) urate-lowing therapy (ULT) were assessed. Dose of ULT was adjusted till sUA was below $6 \mathrm{mg} / \mathrm{dL}$ and $5 \mathrm{mg} / \mathrm{dL}$ for patients with urate deposition. We screened gout patients who had contraindication or history of failure to normalize sUA for $\geq 3$ months of treatment with the maximum medically appropriate febuxostat (febuxostat-resistance) or allopurinol (allopurinol-resistance) dose as defined by physicians. Furthermore, these screened patients met the traditional criteria of refractory gout except therapeutic reaction [2].Demography and clinical characteristics were recorded. Features between febuxostat-resistance and allopurinol-resistance patients were compared.

Results: (1) Of 683 gout patients who were included, 516 and 167 of them used febuxostat or allopurinol. (2) Age (41.92 \pm 11.58 vs. $42.26 \pm 9.41$ years), Male gender ( $97.50 \%$ vs. $97.01 \%)$, duration of gout $(5.78 \pm 4.74$ vs $5.05 \pm 4.72$ years) and sUA $(6.30 \pm 2.50$ vs. $6.67 \pm 2.14 \mathrm{mg} / \mathrm{dL})$ were similar between febuxostat group and allopurinol group $(P>0.05)$. (3) Dose of febuxostat or allopurinol were $47.28 \mathrm{mg} /$ day and $178.24 \mathrm{mg} /$ day. (4) Sixteen patients were febuxostat-resistance, while 6 patients were allopurinol-resistance. Prevalence rates of treatment resistance were comparable between groups (3.10\% vs. $3.59 \%, P>0.05)$. (5) Some parameters were different between resistance patients and non-resistance patients in both groups (Table 1, $P<0.05)$. However, characteristics of febuxostat-resistance and allopurinol-resistance patients were similar $(P>0.05)$.

Table 1 Characteristics of gout patients in febuxostat group and allopurinol group

\begin{tabular}{|c|c|c|c|c|}
\hline \multirow[t]{2}{*}{ Parameters } & \multicolumn{2}{|c|}{ Febuxostat Group } & \multicolumn{2}{|c|}{ Allopurinol Group } \\
\hline & $\begin{array}{l}\text { Non-resistance } \\
\quad(n=500)\end{array}$ & $\begin{array}{l}\text { Resistance } \\
\qquad(\mathrm{n}=16)\end{array}$ & $\begin{array}{c}\text { Non-resistance } \\
\quad(n=161)\end{array}$ & $\begin{array}{l}\text { Resistance } \\
\qquad(\mathrm{n}=6)\end{array}$ \\
\hline Age (year) & $41.93 \pm 11.65$ & $41.67 \pm 9.58$ & $42.22 \pm 13.33$ & $44.50 \pm 16.98$ \\
\hline Male Gender (\%) & 97.40 & 100.00 & 96.89 & 100.00 \\
\hline BMI $\left(\mathrm{kg} / \mathrm{m}^{2}\right)$ & $25.44 \pm 3.46$ & $26.22 \pm 3.47$ & $25.86 \pm 3.97$ & $25.60 \pm 6.42$ \\
\hline $\begin{array}{l}\text { Duration of gout } \\
\text { (years) }\end{array}$ & $5.75 \pm 4.76$ & $7.00 \pm 3.97^{\star}$ & $4.96 \pm 4.73$ & $7.75 \pm 2.62^{*}$ \\
\hline $\begin{array}{l}\text { Flares in previous } \\
18 \text { months (times) }\end{array}$ & $1.31 \pm 0.44$ & $3.67 \pm 0.70^{*}$ & $1.13 \pm 0.24$ & $3.25 \pm 0.50^{*}$ \\
\hline $\begin{array}{l}\text { Presence of } \\
\text { Tophi (\%) }\end{array}$ & 23.80 & $100.00^{*}$ & 14.90 & $100.00^{*}$ \\
\hline $\begin{array}{l}\text { Presence of } \\
\text { Complication (\%) }\end{array}$ & 35.8 & $100.00^{*}$ & 31.06 & $100.00^{*}$ \\
\hline $\mathrm{sUA}(\mathrm{mg} / \mathrm{dL})$ & $6.21 \pm 2.47$ & $9.13 \pm 1.24^{*}$ & $6.42 \pm 2.32$ & $10.15 \pm 3.55^{\star}$ \\
\hline $\mathrm{SCr}(\mu \mathrm{mol} / \mathrm{L})$ & $100.67 \pm 15.03$ & $163.96 \pm 29.41^{*}$ & $96.93 \pm 22.91$ & $133.75 \pm 31.60$ \\
\hline $\operatorname{ESR}(\mathrm{mm} / \mathrm{L})$ & $24.59 \pm 19.28$ & $42.83 \pm 21.13^{*}$ & $27.49 \pm 24.10$ & $56.50 \pm 28.12^{*}$ \\
\hline $\mathrm{CRP}(\mathrm{mg} / \mathrm{L})$ & $18.92 \pm 18.59$ & $28.81 \pm 23.85^{*}$ & $23.12 \pm 22.63$ & $32.28 \pm 23.64 *$ \\
\hline
\end{tabular}

${ }^{\star} P<0.05$ compared with non-resistance patients in the same group.

$B M I$ body mass index, $S U A$ serum uric acid, $S C r$ serum creatinine, ESR erythrocyte sedimentation rate, CRP C-reactive protein

Conclusion: Febuxostat-resistance is a potential criterion for refractory gout, because febuxostat-resistance patients shares similar characteristics of patients with refractory gout.

References:

[1] Neogi T, Jansen TL, Dalbeth N, et al. 2015 Gout classification criteria: an American College of Rheumatology/European League Against Rheumatism collaborative initiative. Ann Rheum Dis 2015;74(10):1789-1798.

[2] Lawrence Edwards N, Singh JA, Troum O, et al. Characterization of patients with chronic refractory gout who do and do not have clinically apparent tophi and their response to pegloticase. Rheumatology (Oxford) 2019; pii: kez017.

Acknowledgments: None.

Disclosure of Interests: : None declared

DOI: 10.1136/annrheumdis-2020-eular.1270

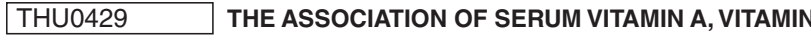 E, AND FOLATE WITH HYPERURICEMIA: AN ANALYSIS OF POPULATION-BASED NATIONALLY REPRESENTATIVE DATA}

Y. Kim ${ }^{1}$, G. T. Kim ${ }^{1}$, J. Kang ${ }^{1} .{ }^{1}$ Kosin University College of Medicine, Kosin University Gospel Hospital, Busan, Korea, Rep. of (South Korea)

Background: Hyperuricemia is an important risk factor for gout as well as hypertension, type 2 diabetes and renal impairment. Although previous studies investigated the association of questionnaire-based micronutrient intake with serum uric acid levels, limited data on serum micronutrients levels in relation to the risk of hyperuricemia especially in Asian population. 